\title{
Agile Software Development during the COVID-19 Pandemic: A Technology Company Survey
}

\author{
Peter Schmidt, Ph.D. \\ University College London \\ peter.schmidt@ucl.ac.uk
}

\author{
Keith Gutfreund \\ Elsevier \\ k.gutfreund@elsevier.com
}

\begin{abstract}
A common baseline is that Agile-based software development is conducted by co-located teams working in well-equipped office workspaces. The COVID-19 pandemic and subsequent lockdowns have cast new light on those assumptions. Suddenly, developers were no longer co-located with their teams and their well-equipped workspaces were vacant. How did the lockdowns, and the speed in which they were implemented, affect developers and development efforts? Did the lockdowns lead to diminished product quality? How was employee productivity impacted? A survey questionnaire was created to answer these questions.
\end{abstract}

\section{Background}

Leading proponents of Agile software development and management practices have long recommended the benefit of co-locating office workers. In Agile Software Development [1], the author dedicates an entire chapter on how information "radiates" between team members based on their location in the office and work environment. Focusing on the costs to projects, Cockburn [1] writes:

"We have seen three separate effects that office layout has on communication costs within a project:

- The lost-opportunity of not asking questions

- The overall costs of detecting and transferring information (erg-seconds)

- The reduction in cost when people discover information in background sounds (osmotic communication)“"

In conclusion, the author argues that having team members located in closer physical proximity reduces the cost of software development.

Likewise, in his book Extreme Programming Explained [2], Kent Beck states that he realised "...how important it is to sit together, to communicate with all your senses." (ch. 7, p.37)
In Scrum, the most popular agile methodology by far, according to the 2020 State of Agile Report [3], activities such as 'daily standups', 'sprint planning and reviews' imply participants to be physically present in the same office space [4].

At the same time, realising co-location has been a challenge for some organisations:

- Development teams and stakeholders may be distributed over different offices, sometimes spanning time-zones

- Development teams may consist of "inhouse" employees (permanent members of staff) and "off-shore" or contract workers (either on or off the premises)

Authors do recognise this. E.g., in [2], Kent Breck writes that "the values of XP are just as suited to multisite development as they are to teams that sit together" (ch. 22) and "does the practice of sitting together mean that multisite teams can't do XP?... the simple answer is No". (ch. 7).

In addition, emerging communication tools and technologies have not only helped to bridge the "geographical gap" between distributed teams but have also opened opportunities for some teams and workers to work remotely at least part of the time. Even before the onset of the coronavirus pandemic, remote working had increased significantly. For example, the Chartered Institute of Personnel and Development (CIPD) in the UK reported in 2020 that "...working from home has increased by $80 \%$ in 20 years to reach $5.3 \%$ of workers", with the highest percentages of workers in the IT and communication sector [5]. A similar trend can be seen in other countries such as e.g., the US [6]. In June 2020, Stanford's Institute for Economic Policy Research (SIEPR) [7] reported that " 42 percent of the U.S. labor force [is] now working from home full-time.” In stark contrast, Bloom [8] reported that this number was only $0.75 \%$ in 1980 and $2.4 \%$ in 2010 .

Since the outbreak of the coronavirus pandemic in early 2020, remote working has increased sharply. During lockdown, some companies and organisations 
(such as RELX and UCL) closed their offices - often at short notice - to all but the most essential workers, with most teams working remotely. Consequently, a number of traditional practices, such as "daily standups", "pair programming", and "sprint meetings", had to adapt quickly.

With the sudden shift from co-located teams to remote working, the global pandemic may be regarded as a turning point in working practices. This may affect working environments in the period following the pandemic, be that through an increase in full-time home workers, or a hybrid approach between working remotely and in the office.

Therefore, the assumptions regarding workspaces made by authors Beck [2] and Schwaber [4] on Agile software development methodologies and their effectiveness on team productivity will need to be revisited.

\section{Research Approach and Methodology}

In assembling this questionnaire, we looked at several key traits of a software development effort, e.g., the team's efficiency, effectiveness, productivity, and ability to innovate. These traits are the focus of this paper. The survey also examined team members' self-assessment of their performance and job satisfaction. Those questions may be examined at a future date. For each of the key traits, the survey asked respondents to compare their work with their prelockdown experience. Some of the survey questions permitted free-form comments which provided additional insight.

We would like to acknowledge that we (the authors) anticipated that the lockdown would adversely impact development teams and development efforts. However, at the time of the survey there was no known precedent for backing out of Agile's key colocation principle. To keep our bias in check, and lacking any actual prescience, the questions posed in the survey were quite broad.

The survey was conducted in May and June of 2020 , approximately two to three months into forced business lockdowns. Teams had only this limited time to become accustomed to the new normal way of working. There was no opportunity for planning or training to facilitate this sudden transition. A future study may look at how the teams have adapted over time.

Co-location of development teams, meaning teams that are physically present in the same space at the same time, has long been a hallmark of Agile development practices [2 Beck], [4 Schwaber]. It is commonly accepted that non-co-located teams, or teams with members separated by geography, by time, or by both geography and time, are not as effective as co-located teams [1]. When the COVID-19 pandemic forced a lockdown of most businesses, including those involved in software development, the same teams that were once co-located were transformed overnight into geographically separated teams. Furthermore, the separation was $100 \%$. This provided the perfect opportunity to validate key Agile methodology assumptions: did pre-pandemic, co-located teams perform differently? Which teams were more efficient, effective, and productive? Which teams were more innovative?

\section{Methodology}

We designed, tested, and implemented a survey questionnaire for a conglomerate business enterprise, the RELX Group, focusing primarily on two of its companies, Elsevier and LexisNexis. The survey was only in English and was broadly distributed to software developers and software development managers at Elsevier and LexisNexis. It is important to note that prior to the lockdown, software development teams at RELX were generally majority co-located, but not $100 \%$ co-located. This experience of working with partially co-located teams likely had an impact on the ease of moving to a fully distributed workforce. In this respect we believe that RELX is quite like other multinational enterprises.

\subsection{The Survey}

The survey was available between May and June of 2020. The SaaS platform Alchemer (formerly SurveyGizmo) was used to develop and host the survey. The survey contained 27 specific, closedended questions, part of which were directly related to software development with an Agile methodology, others related to changes due to COVID-19 induced lockdowns. A single question on employed Agile methodologies allowed the user to write in a value if their methodology was not listed. Each question was multiple choice, and only a single answer was permitted for any question. We selected this format to ensure clarity of analysis; we understood that such a strict format could limit insight from more loquacious respondents.

The purpose of the survey was made clear in a brief email describing the collaboration between University College London (UCL) and Elsevier. The survey was also announced at internal group meetings. Both software developers and managers were welcomed to participate. The survey was stopped after two months, and all responses were anonymous. A 
total of 216 participants began the survey of which 164 (75.9\%) viewed or answered most questions. We surmise that many of those who did not complete the survey were not Agile practitioners or were not participating in an Agile-oriented development effort.

The Alchemer platform hosted the survey and compiled the results. To facilitate comparing the strength of survey responses to a pre-lockdown benchmark value, a comparative or Likert scale, as recommended by Alreck and Settle [9], was employed. Three-level comparative items were consistently structured as follows: smaller/fewer, same as before, larger/greater. As per [9], this yielded equal interval data for analysis. We employed this approach in Questions 18-26, where lockdown and pre-lockdown observations were compared. For example, Question 26 asked if the respondent has more ability to innovate now than before the lockdown, with answer choices of More Ability to Innovate, About the Same, and Less Ability to Innovate. As is common practice, survey results were exported to a comma separated value (CSV) file and analyzed using Microsoft Excel.

The survey structure and the individual questions are described starting in section 3.2 below. The survey results and analysis are discussed in section 4 . Results and Analysis.

\subsection{Survey Structure}

The survey was logically divided into six parts:

1. About the Respondent (Q1-8)

2. Agile Methodologies and Practices (Q9-10)

3. Software Development Practices (Q11-15)

4. Interruptions (Q16)

5. Measuring the Effect of the Lockdown (Q17-26)

6. Post-lockdown Working Preference (Q27)

Each of the parts is described below. The survey questionnaire is available online [10].

\subsubsection{About the Respondent}

The first part queried about the respondent: their role, geographic location, and the respondent's team: team size and percentage co-located (before lockdown). The first question of the survey asked if the respondent was working independently or as part of a team. A selection of working independently would end the survey. Continuing to the team information, the 2020 Scrum Guide, by Schwaber and Sutherland [11], recommends that Scrum teams should be comprised of 10 or fewer people, while the 2017 Scrum Guide, also by Schwaber and Sutherland [12], suggests team sizes of 3 to 9. Given our own experience with development teams in RELX,
Question 6 presented the user with choices of 1-5, 612 , or more than 12 .

To identify the respondent's role, we relied on the definition of traditional roles in an Agile development effort [2]. Scrum is a development framework often associated with Agile Methodology although it originated in a 1986 paper by Takeuchi and Nonaka [13]. Industry-wide, Scrum is currently the most popular Agile framework, with at least $75 \%$ respondents of the 2020 State of Agile Report practicing Scrum or a hybrid of Scrum [3]. Takeuchi and Nonaka define Scrum development teams as being cross-functional, comprised of people fulfilling different development functions. The role question of the survey (Question 2) was therefore limited to a choice of developer, manager, or part managing and part developing.

To better understand the respondent's working organisation, Question 3 queried for their geographical location and Question 4 for whether they were an employee or contractor.

\subsubsection{Agile Methodologies and Practices}

The second part of the survey queried about the specific Agile practices employed, since nearly all development efforts at Elsevier and LexisNexis utilize Agile practices. The questions in this section included which Agile methodologies were used as well as the sprint duration. Question 9 asked the respondent to choose the Agile Methodologies they use. We offered the most common choices from the 14th Agile Survey [3], i.e., Scrum, Extreme Programming (XP), Kanban, Lean, SAFe, Scrumban, Scrum XP hybrid, plus respondent-supplied values for Custom hybrid and Other.

Question 10 asked about sprint duration. The Scrum Guide [11] states that sprints "are fixed length events of one month or less", whereas in Extreme Programming (XP), iterations are recommended to be 1 to 4 weeks [2]. Note that in [2], Beck compartmentalizes work product in iterations and not sprints. Poppendieck and Poppendieck [14] (ch. 2) recommends using consistent-length time-boxed work iterations, and notes that there is no single best duration; Poppendieck says that many find that a onemonth time-box to be useful while others may prefer two weeks, six weeks, or even ten weeks, although the longer duration time-boxes are coupled with daily builds and weekly testing. With this in mind, Question 10 asks "How long is your (usual) iteration/sprint" with choices of 1 week, 2 , weeks, 3 weeks, 4 weeks or more, or variable duration. 


\subsubsection{Software Development Practices}

The third part of the survey checked specific software development practices including build, integration, and release frequency, time required to correct errors, lead time to implement a feature, and portion of the product time spent on feature development. We hypothesized that if there were any side effects of the lockdown then they would be observed by alterations to development practices.

Question 11 asked the respondent for the build and integration frequency. In many organisations, well-established development teams are supported by source control management software with infrastructure supporting automatic building with continuous integration (CI). Such teams would be able to build and integrate code changes daily or even more frequently. Many consider this to be a DevOps best practice [15] as it allows rapid surfacing of potential defects [16]. In Question 11 the respondent could select from Daily (or more often), Weekly (or more often), Once per iteration/sprint, Several iterations/sprints or months, Unsure, and No regular releases/builds.

Distinct from the build and integration frequency is the release frequency. In the software development life cycle (SDLC), the release is the event where software is made available to the end user. Therefore, to be consistent with Question 11 (Build and Integration Frequency) and Question 10 (Iteration/Sprint Length), Question 12 "What is your release frequency" has choices of Daily, Weekly, Monthly, Several Months, Not Sure, and No regular releases.

Question 13 was included to assess the responsiveness of Agile teams to program errors. It asked for mean time to restore - the time between when an error is reported and when a fix is delivered.

Questions 14 and 15 focused on how the lockdown affected the time required for planning and developing new features A fundamental principle of Agile is that of delivering incremental value in fixedlength iterations. The Agile Manifesto exhorts the reader to "Deliver working software frequently, from a couple of weeks to a couple of months, with a preference to the shorter timescale" [17] The Scaled Agile Framework (SAFe) methodology describes the application of Agile to large development efforts comprising multiple Agile teams [18]. SAFe recognizes that groups of Agile teams collectively working together will jointly deliver software as program increments (PIs) on an extended schedule. "PIs are typically established as a fixed $8-12$ weeks period, comprised of $3-5$ development Iterations, followed by one Innovation and Planning (IP) Iteration" [18].

\subsubsection{Interruptions}

The challenge of working during the lockdown was influenced by a number of factors. For most employees, their home residence became the new lockdown workplace.

In Bloom's study [8] of one Chinese company, a random selection of call-center workers were assigned to work from home while the other workers continued working from their office. Bloom noted that home worker individual performance increased by $13 \%$ compared to workers working in the office. The 13\% improvement was due to fewer work breaks, less time off, and fewer sick days. Remarkably, home workers also had a $50 \%$ lower attrition.

In Bloom's China study, the home workers were afforded the same equipment and access as the office staff. This was not universally the same experience for those suddenly forced to work from home during the pandemic. Toniolo-Barrios and Pitt [19] noted the following challenges for the suddenly homebound workers: lack of designated home office space forcing improvised work setups in living rooms, kitchens, bedrooms; closure of schools forcing working parents to supervise children learning from home; difficulty in concentrating due to "ambient distractions such as ringing doorbells, noisy pets, and interrupting children." Fosslien and Duffy [20] noted that extended video conferencing, aka "Zoom fatigue", is leading to increased worker exhaustion.

For our purposes we thought it would be easiest to quantify any change in worker productivity by measuring changes in context switching for both work meetings and other ad-hoc requests. Question 16 asked for the percentage per day that the user spent context switching: less than $20 \%, 21-50 \%$, and more than $50 \%$. At the time our survey was run - early into the pandemic lockdown - we hypothesized that context switching may have been an important factor in productivity. Since then, several studies have begun to examine how Agile development has been affected by the pandemic. See [21], [22], [23].

\subsubsection{Measuring the Effect of Lockdowns}

The survey was released approximately two months into the lockdown, and the authors were just beginning to observe and to hear of anecdotal evidence of effects on the worker, the team, and the products being developed. This next section of the survey attempted to gauge the extent of any such impact. In particular, we attempted to assess whether the 
lockdown was associated with positive or negative effects on the worker's productivity, the team's productivity, and the quality of produced software. Our early suspicion was that the lockdown was adversely impacting work and work product.

Question 17, 18, and 19 asked how specific engineering practices may have changed as compared to before the lockdown. Question 17 asked if the build/integration frequency during the lockdown decreased, remained unchanged, or increased, as compared with before the lockdown. Similarly, Question 18 asked if the release frequency decreased, remained unchanged, or increased during this same period. Question 19 asked how much time the team spent on feature development during the lockdown, compared with effort before the lockdown.

Questions 20 and 21 relate to personal and team productivity, comparing both frequency of interruption, as measured by context switching, as well as team productivity, before and during the lockdown. Questions 22 and 23 asked about quality and value. Iterative development cycles with continuous delivery of value, are hallmark principles of Agile methodology. These questions asked only how the quality and value changed during the lockdown: was the quality better, the same, or worse than before, and was the team able to deliver value more quickly, the same, or less quickly than before. Question 26 asked about innovation: did the respondent have more ability to innovate, less ability to innovate, or about the same ability.

Questions 24 and 25 relate to work satisfaction during the lockdown vs before the lockdown. Question 24 asked if customers were more satisfied, less satisfied, or about the same. Question 25 asked if colleagues were more satisfied with their work, less satisfied with their work, or about the same.

\subsubsection{Post-lockdown Working Preference}

Question 27, the last survey question, asked the respondent's preference to continue working solely from home after the lockdown were lifted, versus returning to the office either part time or full time.

\section{Results and Analysis}

\subsection{COVID-19 Related Office Closures at RELX}

On Tuesday, March 10, 2020, Elsevier announced that their offices in the US, London, Amsterdam, and Chennai would close for one day during the following week, to stress test the technology infrastructure for possible office closures. However, on Tuesday, March 17, 2020, Elsevier announced that all US office locations would be closing (except for essential services) at the end of business on the following day, Wednesday, March 18th. Employees had one day to pick up their belongings and to prepare to work from home. At the end of the workday on Thursday, March 19, 2020, LexisNexis announced that their Raleigh Technology Center was closed, and employees could make an appointment to pick up essential equipment to work from home [24]. Offices at other Elsevier and LexisNexis locations were announcing closures as well. As of May 2021, Elsevier and LexisNexis office locations still have not yet opened for employee occupancy.

The survey, Agile Practices During COVID-19 Lockdown, was first announced on May 7, 2020, approximately seven weeks after the office closures began. The survey announcement was broadly distributed by email among members of the technical staff of LexisNexis and Elsevier. An email announcing the survey briefly described its intent this way: "Today we also announced an Agile survey on changing work habits during the Covid-19 pandemic." A total of 216 participants took the survey of which 164 (75.9\%) answered all questions. The geographic distribution of respondents was $65 \%(141 / 216)$ from the Americas, $24 \%(52 / 216)$ from the UK, $7 \%$ (15/216) from Europe, and $4 \%$ (8/216) from Asia, Russia, and the Middle East. The survey response rate was rather low; we estimate that about $10 \%$ of the targeted population responded. The survey was closed on June 11, 2020.

We surmise that many of those who did not complete the survey were not Agile practitioners or were not participating in an Agile-oriented development effort.

\subsection{Survey Duration}

The survey launched approximately seven weeks after the lockdown began and it remained open for under two months. Although this brief length of time into the lockdown seemed suitable for an earlylockdown snapshot, it was expected that many aspects of worker performance would continue to change over time. Consider two examples: first, home office equipment would likely have improved as employees were able to improve their workspaces. Second, as the lockdown wore on. fatigue and other challenges to worker productivity may have degraded the workers' ability to perform. While potentially useful, additional point snapshots were not collected so as not to further contribute to worker fatigue. 


\subsection{Respondents' Backgrounds}

The survey was intended to assess changes in the Agile process brought about by the lockdown. Question 1 of the survey asked if the respondent was working on a team. If not working on a team, then the Agile questions were irrelevant, and the survey ended for that respondent. Of the 216 responses, 207 said that they were working on a team.

Survey Question 2 and Question 5 sought to determine if the user was a contractor (likely temporary) and if they represented an outside firm. Only one person said that they were a contractor, and $88 \%$ of the people were RELX employees. Only a small number of people claimed to work for a small company.

Question 3 asked where the respondent lived. One third of the respondents were from Europe, the Middle East and Africa, and nearly two thirds were from the Americas. A small number were from Asia. Survey responses were not further broken down by location.

The survey questions largely compared how the Agile development experience changed for the user in the weeks immediately after the lockdown. A seminal and singularly important characteristic of any Agile team is their co-location. After the lockdown, all teams worked from home, hence, team members were not co-located. Pre-lockdown, the team co-location distribution is taken from Survey Question 7 and is shown graphically in Figure 1.

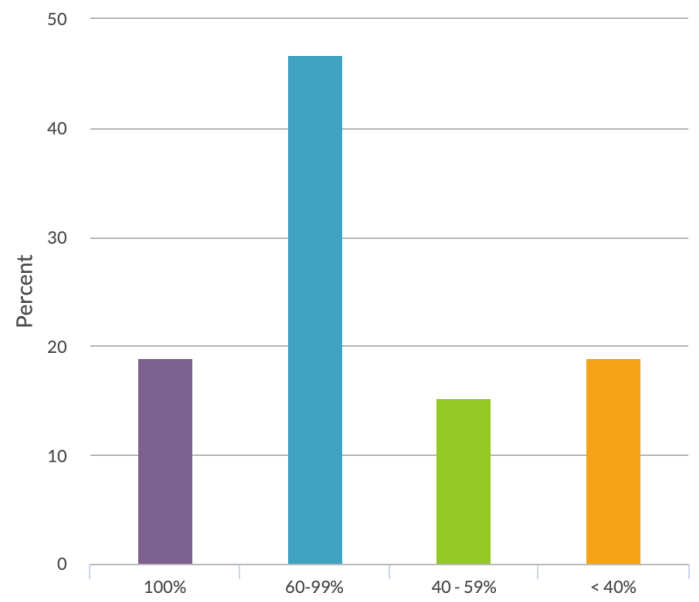

Figure 1. Team co-location pre-lockdown

\footnotetext{
${ }^{1}$ A significance level (alpha) of .05 was used for all statistical tests.
}

\subsection{Research Questions}

The analysis is organized around four research questions of development strength: What impact did the lockdowns have on the team's efficiency (RQ1), effectiveness (RQ2), productivity (RQ3), ability to innovate (RQ4)? These research questions are considered in detail in the Results and Analysis section of the paper.

\subsubsection{Research Question Q1: Efficiency}

Change in efficiency, as estimated by frequency of software build and developer interruption, is encapsulated in survey questions Q17: Build/Integration Frequency, and Q20: Context Switching.

Figure 2 shows the changes by team co-location and in aggregate for the build/integration frequency. Post-lockdown, $88 \%$ of respondents reported unchanged build/integration frequency with the remaining $12 \%$ of respondents about equally reporting increased and decreased frequency. Team co-location was unrelated to changes in build/integration frequency, $\chi^{2}(\mathrm{df}=6 \mathrm{~N}=153)=5.71, \mathrm{p}=.46 .{ }^{1}$

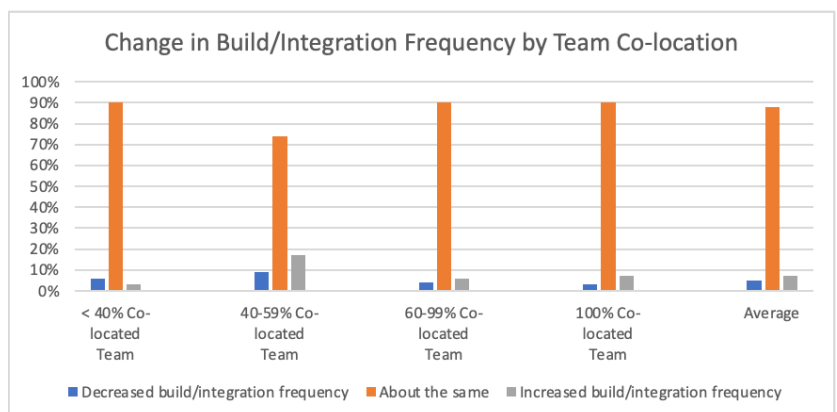
Figure 2. Q17: Change in post-lockdown build/integration frequency by team co- location

In contrast, Q20: Context Switching, as shown in Figure 3 , shows a marked post-lockdown change, with an average of $35 \%$ reporting more time spent context switching and $12 \%$ reporting less time context switching than during pre-lockdown. Observe also the increased context switching interruptions for those teams that were more co-located before the lockdown vs lesser co-located teams. 


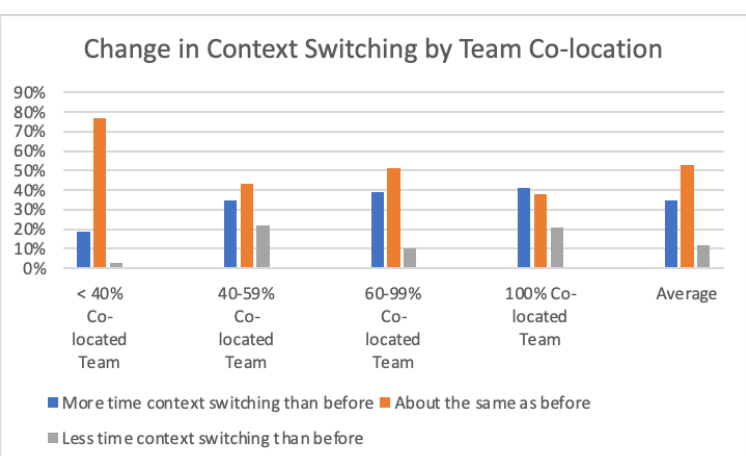

Figure. 3. Q20: Change in context switching

A chi-square test of independence was performed to examine the relation between changes in context switching (post-lockdown) and team co-location strata (pre-lockdown). We found that the change reported in context switching differed significantly by team colocation strata, $\chi^{2}(\mathrm{df}=6 \mathrm{~N}=154)=13.86, \mathrm{p}=.03$. Tables 1 and 2 . show the contingency and expected values for the context switching times for each team's co-location strata.

For a further quantitative analysis, we partitioned the team co-location variable data into two strata, < $40 \%$ co-located team and $>=40 \%$ co-located team. We found a significant relationship between the two strata and context switching, $\chi 2(\mathrm{df}=2 \mathrm{~N}=154)=9.89 \mathrm{p}<$ .01 . In contrast, the context switching "correlation" for respondents in the other partitions of $40-59 \%, 60-99 \%$ and $100 \%$ teams was not significant at $.31, .48$, and .14 respectively, $\boldsymbol{\chi} 2(\mathrm{df}=2, \mathrm{~N}=154)=9.89$.

Our interpretation is that the least co-located teams were already the most experienced at working decentralized and were less likely to see an increase in context switching interruptions due to working away from the office. Similar observations and conclusions also appear to hold at varying degrees for other questions, such as Q21 Productivity.

Table 1. Context switching contingency table

\begin{tabular}{|l|r|r|r|r|r|}
\hline & $\begin{array}{l}\text { Team } \\
\text { Co-lo } \\
<\mathbf{4 0 \%}\end{array}$ & $\begin{array}{l}\mathbf{4 0 -} \mathbf{5 9 \%} \\
\mathbf{6 0}-\end{array}$ & $\begin{array}{l}\mathbf{1 0 0 \%} \\
\mathbf{9 9 \%}\end{array}$ & Margin \\
\hline More & 6 & 8 & 28 & 12 & 54 \\
\hline Same & 24 & 10 & 36 & 11 & 81 \\
\hline Less & 1 & 5 & 7 & 6 & 19 \\
\hline Margin & 31 & 23 & 71 & 29 & 154 \\
\hline
\end{tabular}

Table 2. Context switching expected values

\begin{tabular}{|l|r|r|r|r|}
\hline & $\begin{array}{l}\text { Team } \\
\text { Co-lo } \\
<\mathbf{4 0} \%\end{array}$ & $\mathbf{4 0 - 5 9 \%}$ & $\mathbf{6 0 - 9 9 \%}$ & $\mathbf{1 0 0 \%}$ \\
\hline More & 10.87 & 8.06 & 24.90 & 10.17 \\
\hline Same & 16.31 & 12.1 & 37.34 & 15.25 \\
\hline Less & 3.82 & 2.84 & 8.76 & 3.58 \\
\hline
\end{tabular}

\subsubsection{Research Question Q2: Effectiveness}

Change in effectiveness, as estimated by work quality, and delivered value, is encapsulated by questions Q22: Change in Work Quality, and Q23: Change in Delivering Value. Figures 4 and 5 show the changes by team co-location and in aggregate. Both work quality and delivered value were largely unchanged with around $80 \%$ reporting that the team's work post-lockdown was about the same as prelockdown. Nearly equal numbers reported increased quality (9\%) and decreased quality (7\%). Similarly, the team's ability to quickly deliver value was largely unchanged $(76 \%)$ with nearly equal numbers reporting that value was delivered faster $(11 \%)$ vs slower $(13 \%)$.

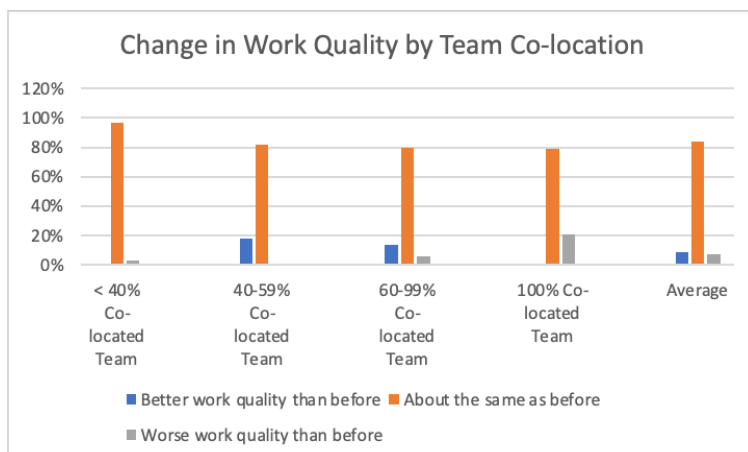

Figure. 4. Q22: Change in work quality

A closer examination of the strata, however, revealed valuable information.

A chi-square test of independence was performed to examine the relationship between changes in work quality (post-lockdown) and team co-location strata (pre-lockdown). We found that the work quality differed significantly by team co-location strata, $\chi^{2}$ $(\mathrm{df}=6 \mathrm{~N}=153)=13.86, \mathrm{p}<.01$.

We also partitioned the team co-location variable data into two groups: a group of the $100 \%$ co-located teams and all other co-located teams $(<100 \%)$. We found a significant relationship between the two groups and their changed work quality (better, same, worse $), \chi^{2}(\mathrm{df}=2, \mathrm{~N}=153)=9.89, \mathrm{p}<.01$. Further analysis of the $100 \%$ co-located group, as shown in Tables 3 and 4 showed lesser work quality delivered by the $100 \%$ co-located teams, $\chi^{2}(\mathrm{df}=1 \mathrm{~N}=153)=$ $9.78, \mathrm{p}<.01$.

Table 3. Delivered quality contingency table

\begin{tabular}{|l|l|l|l|}
\hline $\begin{array}{l}\text { Team } \\
\text { Co-lo }\end{array}$ & $\begin{array}{l}\text { Better+Same } \\
\text { Quality }\end{array}$ & $\begin{array}{l}\text { Worse } \\
\text { Quality }\end{array}$ & Marginal \\
\hline$<\mathbf{1 0 0} \%$ & 119 & 5 & 124 \\
\hline $\mathbf{1 0 0} \%$ & 23 & 5 & 29 \\
\hline Marginal & 142 & 11 & 153 \\
\hline
\end{tabular}


Table 4. Delivered quality expected values

\begin{tabular}{|l|l|l|}
\hline Team Co-lo & $\begin{array}{l}\text { Better+Same } \\
\text { Quality }\end{array}$ & $\begin{array}{l}\text { Worse } \\
\text { Quality }\end{array}$ \\
\hline$<100 \%$ & 115.08 & 8.92 \\
\hline $\mathbf{1 0 0} \%$ & 26.92 & 2.08 \\
\hline
\end{tabular}

For the team co-location groupings of $<40 \%$ and $>=40 \%$, results indicated a marginally significant deterioration of work quality, $\chi 2(\mathrm{df}=1 \mathrm{~N}=153)=9.78$, $\mathrm{p}=.07$. We conclude that while the majority of respondents across all co-location strata had no change in delivered work quality, the teams with the most difficulty were the teams who were the most co-located before lockdown.

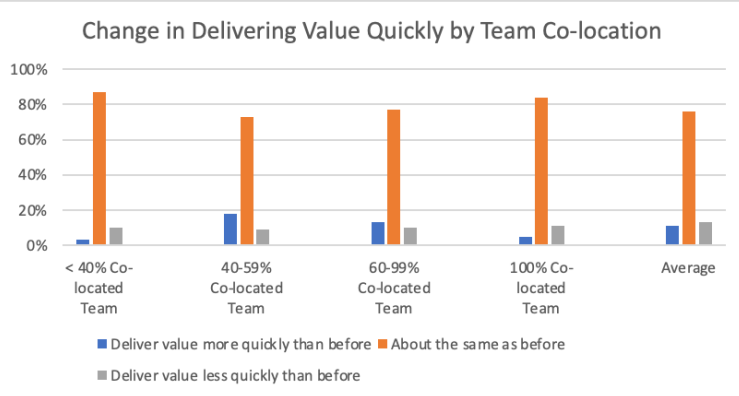

Figure 5. Q23: Change in delivered value

Unlike work quality, there was not a significant relationship between teams' co-location and their ability to deliver value. However, there was a quality drop for the $100 \%$ co-located teams, $\chi 2(\mathrm{df}=2 \mathrm{~N}=152)$ $=6.53, \mathrm{p}=.01$.

\subsubsection{Research Question RQ3: Productivity}

Change in productivity, as estimated by release frequency and self-assessed productivity, is encapsulated in survey questions Q18: Change in Release Frequency, and Q21: Change in Productivity. Figures 6 and 7 show the changes by team co-location and in aggregate for each question. Release frequency (Q18) was largely unchanged with $83 \%$ reporting that the team's work post-lockdown was about the same as pre-lockdown. Nearly equal numbers reported less frequent $(10 \%)$ and more frequent $(7 \%)$ releases. Similarly, the team's productivity (Q21) value was largely unchanged in the aggregate $(65 \%)$, with nearly equal numbers reporting higher productivity (19\%) vs lower productivity $(16 \%)$.

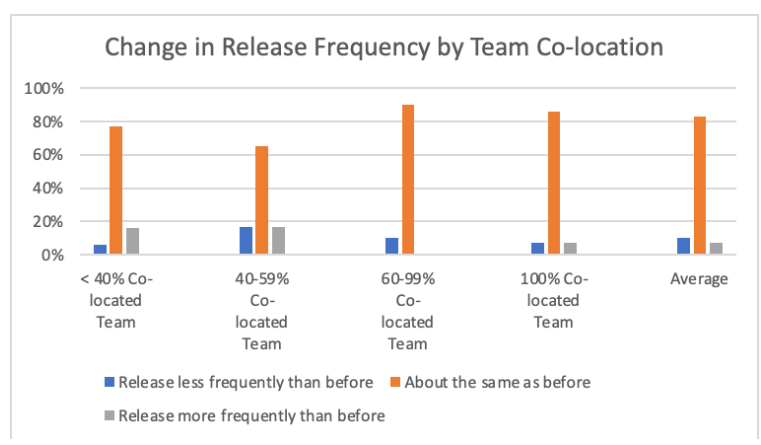

Figure. 6. Q18: Change in release frequency

A chi-square test of independence revealed a significant relationship between team co-location and release frequency, $\chi 2(\mathrm{df}=6 \mathrm{~N}=154)=15.39, \mathrm{p}=.02$. Unexpectedly, this relationship was not consistent across co-located teams:

a. teams in the $<40 \%$ co-located group were able to release more frequently post lockdown, $\chi 2(\mathrm{df}=1$ $\mathrm{N}=154)=4.73, \mathrm{p}=.03$.

b. teams in the 40-59\% co-located group reporting increases in both higher and lower release frequencies, $\chi 2(\mathrm{df}=2 \mathrm{~N}=154)=6.64, \mathrm{p}=.04$.

This may be attributed to team-specific situations and merits future investigation.

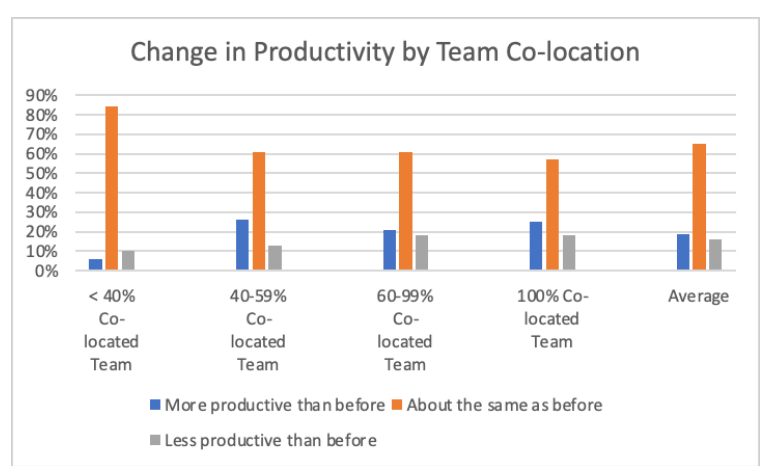

Figure 7. Q21: Change in productivity

In the aggregate, we were surprised to find that teams reported increased productivity during the lockdown. While we did not find a significant relationship between team co-location and productivity in the aggregate, we did find that the < $40 \%$ teams' productivity did show a significant lack of change, $\chi^{2}(\mathrm{df}=2 \mathrm{~N}=154)=6.73, \mathrm{p}=.03$. Since the $<40 \%$ co-located teams were already the most non-colocated, it is not surprising that this group did not report as much improvement or as much decline.

\subsubsection{Research Question Q4: Innovation}

Question 26 asked for the Change in ability to innovate, and the results, grouped by team-co-location 
and the aggregate are shown in Figure 8. Postlockdown, the ability to innovate was largely unchanged at $63 \%$, and nearly equal numbers reported more ability to innovate $(16 \%)$ vs less ability to innovate $(20 \%)$.

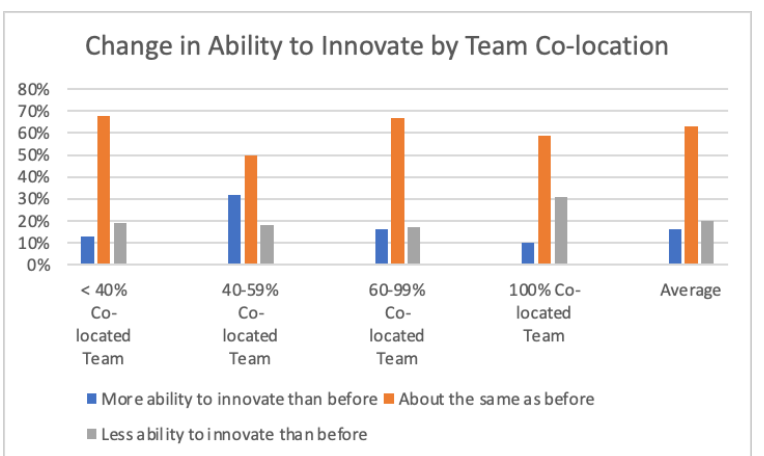

Fig. 8. Q26: Change in ability to innovate

\section{Conclusions}

Other studies have examined the challenges of Agile software development when teams are dispersed geographically and temporally. [25]. By leveraging a global workforce, distributed software development (DSD) efforts are increasingly found in both large and small companies, including the RELX companies Elsevier and LexisNexis.

DSD introduces new challenges, including navigating socio-cultural norms [25] and establishing trust [26]. Bose [27] analyzed twelve different companies to understand how their distributed Agile software efforts fared with workplace challenges including communication, culture, and trust.

While studied extensively, DSD efforts generally benefit from a thoughtful and deliberate development environment. Developers are recruited, teams are assembled, and projects are planned with DSD in mind. The COVID-19 pandemic lockdowns, however, did not allow for these luxuries. Development teams were immediately transformed to a $100 \%$ distributed workforce. The sudden lockdowns allowed no opportunity for planning, for training, or even for properly equipping teams and workspaces. This survey attempted to provide new insight when a sudden and complete DSD transformation occurs.

Three of the four summary measures of development strength, i.e., effectiveness (RQ2), productivity (RQ3) and ability to innovate (RQ4), were largely unchanged in the aggregate, postlockdown compared to pre-lockdown. However, responses to the two survey questions comprising efficiency, i.e., context switching (Q20) and build/integration frequency (Q11), did not follow the same pattern. Like the other measures, build and integration frequency was largely unchanged pre- and post-lockdown. At the same time, $35 \%$ of respondents reported increased context switching during the lockdown. How then, do we rationalize increased context switching with the relative stability of the other measures? Put another way, if context switching is an approximate measure of interruption, then how did respondents maintain their development strength in the presence of increased interruption?

Now at just over a year into the pandemic lockdowns, considerable evidence is emerging of the multiple challenges of working from home during a pandemic [21], [22], [23]. Across the world, many workers were suddenly faced with poor working conditions (equipment, noise, space), the need to manage childcare and eldercare, managing illness, and increased stress from all the above. Despite these challenges, the development strength measures were largely unchanged. Two possible explanations are as follows:

- Workers may have been spending longer hours on their work when working from home, to get the same amount of work done

- Only a minority of the RELX respondents who participated in the survey were working on $100 \%$ co-located teams before the lockdown. As shown in Figure 1, many respondents were already working remotely from their teammates, although most RELX employees did not work regularly from a home office. Thus, most respondents already had some experience working on or with distributed teams before lockdowns.

Although some measures of development strength in our survey were largely unchanged when compared to before the lockdown, several reported changes were, nevertheless, statistically significant for specific strata. These include changes in context switching (Q20), productivity (Q21), work quality (Q22), and delivered value $(\mathrm{Q} 23)$. In general, we found that for those team members who experienced changes in development strength, those who were working on the most co-located teams before the lockdown, reported the most challenges once into the lockdown. Or conversely, those teams with the most distributed (non-co-located) workforce before the lockdown, appeared to adapt best to challenges in the lockdown.

\section{Acknowledgements}

The authors gratefully acknowledge the support of their families, friends, and co-workers during this effort. 


\section{References}

[1] Cockburn, A. (2006). Agile Software Development: The Cooperative Game, 2nd ed., Chapter 3 'Communicating, Cooperating Teams.' AddisonWesley Professional

[2] Beck, K. (2004). Extreme Programming Explained, Addison-Wesley.

[3] 14th State of Agile Report, Version One (2019). https://stateofagile.com/\#ufh-i-615706098-14thannual-state-of-agile-report/7027494, as viewed on April 21, 2021.

[4] Schwaber, K., Beedle, M. (2002). Agile Software Development with Scrum, Prentice Hall.

[5] What's driving the rise in remote working, CIPD (Chartered Institute of Personnel and Development) (2020). https://www.cipd.co.uk/Images/working-fromhome-1_tcm18-74230.pdf, as viewed on June 9, 2021.

[6] Bayern, $\bar{M}$. (2021). How remote work rose by $400 \%$ in the past decade. https://www.techrepublic.com/article/how-remotework-rose-by-400-in-the-past-decade/, as viewed on June 9, 2021

[7] Wong, M. (2020). Stanford research provides a snapshot of a new working-from-home economy. https://news.stanford.edu/2020/06/29/snapshot-newworking-home-economy/, as viewed on April 25, 2021.

[8] Bloom, N., Liang, J., Roberts, J. and Ying, Z., 2014. Does Working from Home Work? Evidence from a Chinese Experiment. The Quarterly Journal of Economics, 130(1), pp.165-218.

[9] Alreck P., Settle R. (2004), The Survey Research Handbook, McGraw-Hill.

[10] Gutfreund, Keith (2021), “Agile Software Development during the COVID-19 Pandemic: A Technology Company Survey", Mendeley Data, V1, doi: $10.17632 / \mathrm{ssj} 7 \mathrm{hwt} 5 \mathrm{c} 2.1$

[11] Schwaber, K., Sutherland, J. (2020) The Scrum Guide, The Definitive Guide to Scrum: The Rules of the Game, p.5.

https://scrumguides.org/docs/scrumguide/v2020/2020Scrum-Guide-US.pdf. As viewed on April 21, 2021.

[12] Schwaber, K. (2017), The Scrum Guide, The Definitive Guide to Scrum: The Rules of the Game, p.7. https://scrumguides.org/docs/scrumguide/v2017/2017Scrum-Guide-US.pdf. As viewed on June 9, 2021.

[13] Takeuchi, H. Nonaka, I., The New New Product Development Game, Harvard Business Review, Jan 1986. https://hbr.org/1986/01/the-new-new-productdevelopment-game as viewed on Apr 21, 2021.

[14] Poppendieck, M., Poppendieck , T. (2003), Lean Software Development: An Agile Toolkit. AddisonWesley.

[15] Atlassian CI/CD What is Continuous Integration? (n.d.). https://www.atlassian.com/continuousdelivery/continuous-integration as viewed on Apr 21, 2021.

[16] Pathania, N. (2021), Learning Continuous Integration with Jenkins, ch. Continuous Integration. Packt.

[17] Agile Manifesto (n.d.). https://agilemanifesto.org. As viewed on June 9, 2021.
[18] Agile Product Delivery (n.d.). https://www.scaledagileframework.com/agile-productdelivery/, as viewed on April 25, 2021.

[19] Toniolo-Barrios, M., Pitt, L. (2020) Mindfulness and the challenges of working from home in times of crisis, Business Horizons, pp. 189-197. doi: 10.1016/j.bushor.2020.09.004.

https://www.ncbi.nlm.nih.gov/pmc/articles/PMC7535 863/, as viewed on April 25, 2021

[20] Fosslien, L., Duffy, M.W. (2020). How to Combat Zoom Fatigue, Harvard Business Review, April 29, 2020. https://hbr.org/2020/04/how-to-combat-zoomfatigue. As viewed on April 25, 2021

[21] Pfeiffer, W. (n.d.). Op-ed: Why next work-from-home phase could be 'death by a thousand cuts' if remote IT doesn't improv. https://www.cnbc.com/2020/09/14/why-next-workfrom-home-phase-could-be-death-by-a-thousandcuts.html. As viewed on April 25, 2021.

[22] Marek, K., Wińska E., Dąbrowski W. (2021). The State of Agile Software Development Teams During the Covid-19 Pandemic. In: Przybyłek A., Miler J., Poth A., Riel A. (eds.) Lean and Agile Software Development. LASD 2021. Lecture Notes in Business Information Processing, vol 408. Springer, Cham. https://doi.org/10.1007/978-3-030-67084-9_2.

[23] Griffin L. (2021) Implementing Lean Principles in Scrum to Adapt to Remote Work in a Covid-19 Impacted Software Team. In: Przybyłek A., Miler J., Poth A., Riel A. (eds) Lean and Agile Software Development. LASD 2021. Lecture Notes in Business Information Processing, vol 408. Springer, Cham. https://doi.org/10.1007/978-3-030-67084-9_11

[24] Private LexisNexis Employee Email

[25] Kahya, M. D., Seneler, C. (2018) Geographical distance challenges in distributed agile software development: Case study of a global company. 2018 3rd International Conference on Computer Science and Engineering (UBMK), pp. 78-83.

[26] Moe, N.B., Šmite D. (2007) Understanding Lacking Trust in Global Software Teams: A Multi-case Study. In: Münch J., Abrahamsson P. (eds) Product-Focused Software Process Improvement. PROFES 2007. Lecture Notes in Computer Science, vol 4589. Springer, Berlin, Heidelberg.

[27] Bose, I (2008) Lessons Learned from Distributed Agile Software Projects: A Case-Based Analysis. Communications of the Association for Information Systems: Vol. 23, Article 34. 